\title{
Myocardial contractility of the isovolumetrically beating isolated rat heart
}

L.M. De Stefano,

L.S. Matsubara and B.B. Matsubara
Departamento de Clínica Médica, Faculdade de Medicina de Botucatu, Universidade Estadual Paulista, Botucatu, SP, Brasil

\section{Correspondence}

B.B. Matsubara

Departamento de Clínica Médica

Faculdade de Medicina de Botucatu UNESP

18618-000 Botucatu, SP

Brasil

E-mail: beatrizm@fmb.unesp.br

Research supported by FAPESP and FUNDUNESP.

Received October 31, 2003

Accepted June 22, 2004

\section{Abstract}

Several indexes of myocardial contractility have been proposed to assess ventricular function in the isovolumetrically beating isolated heart. However, the conclusions reached on the basis of these indexes may be influenced by ventricular geometry rather than contractility itself. The objective of the present study was to assess the performance of widely used contractility indexes in the isovolumetrically beating isolated heart in two experimental models of hypertrophy, the spontaneously hypertensive rat (SHR) and infrarenal aortocava fistula. Compared to normotensive controls $(\mathrm{N}=8)$, SHRs with concentric hypertrophy $(\mathrm{N}=10)$ presented increased maximum rate of ventricular pressure rise $(3875 \pm 526$ vs $2555 \pm 359 \mathrm{mmHg} / \mathrm{s}, \mathrm{P}<0.05)$ and peak of isovolumetric pressure $(187 \pm 11$ vs $152 \pm 11 \mathrm{mmHg}, \mathrm{P}<0.05)$, and decreased developed stress $\left(123 \pm 20\right.$ vs $\left.152 \pm 26 \mathrm{~g} / \mathrm{cm}^{2}, \mathrm{P}<0.05\right)$ and slope of stress-strain relationship $\left(4.9 \pm 0.42\right.$ vs $\left.6.6 \pm 0.77 \mathrm{~g} / \mathrm{cm}^{2} / \%\right)$. Compared with controls $(\mathrm{N}=11)$, rats with volume overload-induced eccentric hypertrophy $(\mathrm{N}=16)$ presented increased developed stress $\left(157 \pm 38\right.$ vs $\left.124 \pm 22 \mathrm{~g} / \mathrm{cm}^{2}, \mathrm{P}<0.05\right)$ and slope of stress-strain relationship $\left(9 \pm 2\right.$ vs $\left.7 \pm 1 \mathrm{~g} / \mathrm{cm}^{2} / \%, \mathrm{P}<0.05\right)$, and decreased maximum rate of ventricular pressure rise $(2746 \pm 382$ vs $3319 \pm 352$ $\mathrm{mmHg}, \mathrm{P}<0.05)$ and peak of isovolumetric pressure $(115 \pm 14 \mathrm{vs} 165$ $\pm 13 \mathrm{mmHg} / \mathrm{s}, \mathrm{P}<0.05)$. The results suggested that indexes of myocardial contractility used in experimental studies may present opposite results in the same heart and may be influenced by ventricular geometry. We concluded that several indexes should be taken into account for proper evaluation of contractile state, in the isovolumetrically beating isolated heart.

\section{Introduction}

Myocardial hypertrophy represents an important adaptive mechanism to hemodynamic overload (1). However, in addition to cell growth there are many structural changes that lead to myocardial remodeling and ven-
Key words

- Myocardial hypertrophy

- Ventricular dilation

- Pressure overload

- Volume overload

$\ldots \ldots \ldots \ldots \ldots \ldots$ tricular failure. Therefore, the assessment of myocardial contractility has a major importance when cardiac hypertrophy is present.

Contractility is a very complex property of the muscle, which plays a major role in heart performance, together with preload, afterload, heart rate, and rhythm. Because all 
of these factors are interrelated and cannot be fully controlled under physiological conditions, there is no ideal index of contractile state that can be used without restrictions. Therefore, in vitro preparations that allow the control of these variables are useful for the analysis of contractility. It should be pointed out that contractility can be described in terms of either force or flow generation capacity and that any specific index may emphasize one property over the other. For instance, the indexes derived from the isovolumetrically beating isolated heart measure only the ability of the myocardium to develop force, since there is no flow (1-4). These indexes are extensively used to analyze the association between myocardial hypertrophy and contractility (1-3). However, even when using these highly controlled conditions, researchers have reported conflicting results. In fact, myocardial hypertrophy has been described as a condition associated with decreased, unchanged, or even increased contractility when heart failure is absent (2,3,5-14). The possible causes for these discrepancies are many and may include the type of hypertrophy, the animal used in the study, the time course of the overload-induced hypertrophy, and the indexes used to measure contractility. For example, Murad and Tucci (15) considered peak isovolumetric developed pressure to be unreliable for the assessment of myocardial contractility in pressure overload-induced concentric hypertrophy in rats, favoring the developed stress index. These investigators did not consider ventricular dilation. In contrast, Brower et al. $(2,3)$ used peak isovolumetric pressure and the pressure-volume relation in the isolated hearts to measure myocardial contractility in volume overload-induced left ventricular hypertrophy in rats. In addition, maximal rate of pressure rise and stress-strain relationship have also been used by several investigators to assess myocardial contractility in the hypertrophied rat heart $(6,7,15-$ 17). Both pressure-volume and stress-strain relationships provide a load-insensitive measure of contractile state. The former may reflect contractility in terms of cardiac pump and the latter, in terms of muscle capacity of force generation.

The objective of the present study was to analyze the performance of widely used contractility indexes in the isovolumetrically beating isolated heart, in two experimental models of hypertrophy associated with either pressure or volume overload.

\section{Material and Methods}

All investigations were performed according to the Guide for Care and Use of Laboratory Animals published by the U.S. National Institute of Health and were approved by the Animal Research Committee of the Medical School of Botucatu, SP, Brazil.

Sixty-three-week-old male spontaneously hypertensive rats (SHR group, $N=10$ ) were used as a model of myocardial hypertrophy associated with pressure overload. Age- and sex-matched Wistar Kyoto rats were used as controls (WKY group, $\mathrm{N}=8$ ).

Volume overload myocardial hypertrophy was induced in sixteen 20 -week-old male Wistar rats submitted to surgery to create an infrarenal aortocava fistula (ACF) by the method of Garcia and Diebold (18), and maintained for eight weeks. The results were compared with those obtained for a SHAMoperated group $(\mathrm{N}=11)$.

All animals were housed under controlled conditions of light (12-h cycles) and constant temperature $\left(25^{\circ} \mathrm{C}\right)$, with standard rat chow diet and water ad libitum. Before euthanasia by thiopental sodium, tail cuff blood pressure was recorded.

Animals were anesthetized with $50 \mathrm{mg} /$ $\mathrm{kg}$ thiopental sodium, $i p$, and received 2000 IU heparin, $i p$. The chest was open through a median sternotomy under artificial ventilation. The ascending aorta was isolated and cannulated for retrograde perfusion with filtered and oxygenated Krebs-Henseleit solu- 
tion maintained at constant temperature and perfusion pressure $\left(37^{\circ} \mathrm{C}\right.$ and $75 \mathrm{mmHg}$, respectively). The Krebs-Henseleit solution had the following composition: $115 \mathrm{mM} \mathrm{NaCl}$, $5.4 \mathrm{mM} \mathrm{KCl}_{1}, 2.5 \mathrm{mMCaCl}_{2}, 1.2 \mathrm{mM} \mathrm{MgSO}_{4}$, $1.15 \mathrm{mM} \mathrm{NaH} \mathrm{SO}_{4}, 1.2 \mathrm{mM} \mathrm{Na}_{2} \mathrm{SO}_{4}, 25$ $\mathrm{mM} \mathrm{NaHCO}_{3}$, and $11 \mathrm{mM}$ glucose. The heart was quickly removed from the chest and connected to the Experimental Apparatus (type 830 Hugo Sachs Electronick, MarchHugstetten, Germany). The main pulmonary artery was cut to vent the right ventricle and a latex balloon was placed into the left ventricle (LV) via the mitral valve orifice. The proximal end of the balloon previously attached to a plastic cannula was connected to a three-way stopcock that permitted filling the balloon with saline and emptying it. The ventricular pressure was measured with a 23XL transducer and a WindoGraph ${ }^{\circledR}$ recorder (Gould Inc., Valley View, OH, USA). In the isovolumetrically beating ventricle, paced at 240 beats/min with an artificial pacer, model 79232 (Hugo Sachs Electronick), the balloon volume was increased in $0.02 \mathrm{ml}$ increments over a diastolic range of $0-25 \mathrm{mmHg}$. The pressure and volume within the balloon were recorded following each increment and corresponded to the left ventricular pressure and volume, respectively. The volume at diastolic pressure zero reflected the ventricular unstressed volume $\left(\mathrm{V}_{0}\right)$ and was used as an index of chamber size. After pressure recordings, the heart was removed from the perfusion apparatus, atria and great vessels were discarded, and the ventricles were separated and weighed.

To assess myocardial peak systolic stiffness in hearts with different LV weight and size, stress $\left(\sigma ; \mathrm{g} / \mathrm{cm}^{2}\right)$ and strain $(\varepsilon ; \%)$ at the LV mid-wall were calculated assuming the LV to be a thick-walled sphere. The following equations were used (19):

$$
\sigma=\left[1.36 \times \mathrm{LVP}^{2} \times \mathrm{LVV}^{2 / 3}\right] /[(\mathrm{LVV}+
$$
$\left.0.943 \times \mathrm{LVW}^{2 / 3}\right]$;

$$
\varepsilon=\left\{\left[\mathrm{LVV}^{1 / 3}+(\mathrm{LVV}+0.943 \times \mathrm{LVW})^{1 / 3}\right] /\right.
$$

$\left.\left[\mathrm{V}_{0}^{1 / 3}+\left(\mathrm{V}_{0}+0.943 \times \mathrm{LVW}\right)^{1 / 3}\right]-1\right\} \times 100$ where $\mathrm{LVV}$ is $\mathrm{LV}$ volume $(\mathrm{ml}), \mathrm{V}_{0}$ is $\mathrm{LVV}$ at a diastolic pressure of $0 \mathrm{mmHg}, \mathrm{LVW}$ is $\mathrm{LV}$ weight $(\mathrm{g})$, and LVP is LV peak isovolumetric pressure $(\mathrm{mmHg})$.

The slopes of linear systolic pressurevolume (PVR) and stress-strain (SSR) relationships were used as load-independent indexes of myocardial contractility $(2-4,20)$. Maximum rate of ventricular pressure rise $(+\mathrm{dP} / \mathrm{dt}), \mathrm{LVP}$ and developed stress were also analyzed.

All statistical analyses were performed using Jandel Sigma Stat 2.0 software. Data are reported as means \pm SD and were compared by the Student $t$-test, with the level of significance set at $\mathrm{P}<0.05$.

\section{Results}

Table 1 shows the morphometric data for rats submitted to chronic pressure overload, compared to control. Systolic blood pressure and normalized LVW were significantly increased in SHR compared to WKY. Left ventricular weight normalized to $\mathrm{V}_{0}$ (LVW/ $\mathrm{V}_{0}$ ) was significantly higher in the SHR group, indicating concentric hypertrophy.

SHR presented an increased $+\mathrm{dP} / \mathrm{dt}$ (3875 \pm 526 vs $2555 \pm 359 \mathrm{mmHg} / \mathrm{s}, \mathrm{P}<0.05)$ and LVP $(187 \pm 11$ vs $152 \pm 11 \mathrm{mmHg}, \mathrm{P}<0.05)$. The developed stress $(123 \pm 20$ vs $152 \pm 26$ $\left.\mathrm{g} / \mathrm{cm}^{2}, \mathrm{P}<0.05\right)$ and the slope of the SSR $\left(4.90 \pm 0.42\right.$ vs $6.60 \pm 0.77 \mathrm{~g} / \mathrm{cm}^{2} / \%, \mathrm{P}<$ $0.05)$ were significantly decreased in the SHR group compared to the WKY group. The slope of the PVR $(252 \pm 120$ vs $242 \pm 92$ $\mathrm{mmHg} / \mathrm{ml}, \mathrm{P}>0.05$ ) was similar in the two groups (Table 2).

The morphometric data obtained for ACF and SHAM rats are shown in Table 3. Compared to control, the ACF group showed reduced systolic blood pressure $(122 \pm 13 \mathrm{vs}$ $154 \pm 27 \mathrm{mmHg}, \mathrm{P}<0.05)$ and decreased LVW/ $/ \mathrm{V}_{0}(4.2 \pm 0.5$ vs $6.7 \pm 0.8 \mathrm{mg} / \mathrm{ml}, \mathrm{P}<$ 0.05). Also, normalized LVW and $\mathrm{V}_{0}$ were increased in the ACF group (LVW/body 
weight: $3.4 \pm 0.5$ vs $2.3 \pm 0.14 \mathrm{mg} / \mathrm{g}, \mathrm{P}<0.05$ and $\mathrm{V}_{0}: 350 \pm 135$ vs $150 \pm 28 \mu \mathrm{l}, \mathrm{P}<0.05$ ), suggesting an eccentric hypertrophy with LV dilatation.

Developed stress $(157 \pm 39$ vs $124 \pm 22 \mathrm{~g} /$ $\left.\mathrm{cm}^{2}, \mathrm{P}<0.05\right)$ and SSR $\left(9 \pm 2 v s 7 \pm 1 \mathrm{~g} / \mathrm{cm}^{2} /\right.$ $\%, \mathrm{P}<0.05)$ were significantly higher in the
ACF group compared to the SHAM group. PVR $(130 \pm 71$ vs $246 \pm 56 \mathrm{mmHg} / \mathrm{ml}, \mathrm{P}<$ $0.05),+\mathrm{dP} / \mathrm{dt}(2746 \pm 382$ vs $3319 \pm 352$ $\mathrm{mmHg} / \mathrm{s}, \mathrm{P}<0.05)$ and LVP $(115 \pm 14$ vs $165 \pm 13 \mathrm{mmHg}, \mathrm{P}<0.05$ ) were significantly decreased in the ACF group, compared to control (Table 4).

Table 1. Chronic pressure-overload rats compared to controls.

\begin{tabular}{lllllll}
\hline & BW $(\mathrm{g})$ & SBP $(\mathrm{mmHg})$ & LVW $(\mathrm{g})$ & LVW/BW $(\mathrm{mg} / \mathrm{g})$ & $\mathrm{V}_{0}(\mu \mathrm{l})$ & LVW/ $(\mathrm{mg} / \mathrm{ml})$ \\
\hline WKY & $482 \pm 59$ & $121 \pm 7$ & $1.07 \pm 0.04$ & $2.24 \pm 0.26$ & $282 \pm 48$ & $3.91 \pm 0.83$ \\
SHR & $371 \pm 21^{*}$ & $204 \pm 17^{*}$ & $1.25 \pm 0.13^{*}$ & $3.35 \pm 0.27^{*}$ & $175 \pm 33^{*}$ & $7.14 \pm 1.35^{*}$
\end{tabular}

BW = body weight; SBP = tail-cuff systolic blood pressure; LVW = left ventricular weight; $V_{0}=$ unstressed left ventricular volume; WKY = Wistar Kyoto rats; SHR = spontaneously hypertensive rats.

${ }^{*} \mathrm{P}<0.05$ vs WKY (Student $t$-test).

Table 2. Isolated heart systolic function indexes in a chronic pressure-overload model.

\begin{tabular}{lccccc}
\hline & $+\mathrm{dP} / \mathrm{dt}(\mathrm{mmHg} / \mathrm{s})$ & LVP $(\mathrm{mmHg})$ & $\mathrm{d} \sigma\left(\mathrm{g} / \mathrm{cm}^{2}\right)$ & $\mathrm{PVR}(\mathrm{mmHg} / \mathrm{ml})$ & $\mathrm{SSR}\left(\mathrm{g} / \mathrm{cm}^{2} / \%\right)$ \\
\hline WKY & $2555 \pm 359$ & $152 \pm 11$ & $152 \pm 26$ & $242 \pm 92$ & $6.6 \pm 0.77$ \\
SHR & $3875 \pm 526^{*}$ & $187 \pm 11^{*}$ & $123 \pm 20^{*}$ & $252 \pm 120$ & $4.9 \pm 0.42^{*}$ \\
\hline
\end{tabular}

$\mathrm{d} \sigma=$ developed stress; $+\mathrm{dP} / \mathrm{dt}=$ maximum rate of pressure rise; LVP = peak of isovolumetric pressure; PVR = slope of the systolic pressure-volume relationship; SSR = slope of the stress-strain relationship; WKY = Wistar Kyoto rats; SHR = spontaneously hypertensive rats.

${ }^{*} \mathrm{P}<0.05$ vs WKY (Student $t$-test).

Table 3. Chronic volume-overload rats compared to controls.

\begin{tabular}{lcccccc}
\hline & BW $(\mathrm{g})$ & SBP $(\mathrm{mmHg})$ & LVW $(\mathrm{g})$ & LVW/BW $(\mathrm{mg} / \mathrm{g})$ & $V_{0}(\mu \mathrm{l})$ & LVWN $(\mathrm{mg} / \mathrm{ml})$ \\
\hline SHAM & $448 \pm 42$ & $154 \pm 27$ & $0.96 \pm 0.08$ & $2.3 \pm 0.14$ & $150 \pm 28$ & $6.7 \pm 0.8$ \\
ACF & $426 \pm 47$ & $122 \pm 13^{*}$ & $1.40 \pm 0.23^{*}$ & $3.4 \pm 0.5^{*}$ & $350 \pm 135^{*}$ & $4.2 \pm 0.5^{*}$
\end{tabular}

ACF = aortocaval fistula; BW = body weight; LVW = left ventricular weight; SBP = tail-cuff systolic blood pressure; $V_{0}=$ unstressed left ventricular volume.

${ }^{*} \mathrm{P}<0.05$ vs SHAM (Student $t$-test).

Table 4. Isolated heart systolic function indexes in a chronic volume overload model.

\begin{tabular}{lccccc}
\hline & $+\mathrm{dP} / \mathrm{dt}(\mathrm{mmHg} / \mathrm{s})$ & LVP $(\mathrm{mmHg})$ & $\mathrm{d} \sigma\left(\mathrm{g} / \mathrm{cm}^{2}\right)$ & $\mathrm{PVR}(\mathrm{mmHg} / \mathrm{ml})$ & $\mathrm{SSR}\left(\mathrm{g} / \mathrm{cm}^{2} / \%\right)$ \\
\hline SHAM & $3319 \pm 352$ & $165 \pm 13$ & $124 \pm 22$ & $246 \pm 56$ & $7 \pm 1$ \\
ACF & $2746 \pm 382^{*}$ & $115 \pm 14^{*}$ & $157 \pm 38^{*}$ & $130 \pm 71^{*}$ & $9 \pm 2^{*}$
\end{tabular}

$\mathrm{ACF}=$ aortocaval fistula; $\mathrm{d} \sigma=$ developed stress; $+\mathrm{dP} / \mathrm{dt}=$ maximum rate of pressure rise; LVP $=$ peak of isovolumetric pressure; PVR = slope of systolic pressure-volume relationship; SSR = slope of stress-strain relationship.

${ }^{*} \mathrm{P}<0.05$ vs SHAM (Student $t$-test). 


\section{Discussion}

In the present study, contrasting results regarding myocardial contractility were obtained for isovolumetrically beating hypertrophied heart depending on the functional index used. Considering the case of concentric hypertrophied left ventricles, LVP and $+\mathrm{dP} / \mathrm{dt}$ would suggest improved contractility. On the other hand, the same ventricles would be considered to show reduced contractility when assessed in terms of developed stress and SSR. These conflicting results indicate an interesting question about which indexes should be used in order to evaluate myocardial contractility in SHR.

According to the literature, contractile indexes decline late in life in SHR, at about 18 months of age, and are associated with clinical signs of heart failure (21). Since our data were obtained for 63-week-old rats, we would assume that myocardial contractility is still preserved and that the indexes that indicate either improvement or worsening are under the influence of other factors, such as ventricular geometry.

In the presence of concentric hypertrophy, the thick-walled ventricle allows increased pressure generation, even without improved myocardial contractility. In the heart without hypertrophy, the contractile state of the LV chamber agrees with the contractile state of the myocyte $(13,14)$. However, in the hypertrophied heart, the contractile state of the LV chamber may differ from that of the sarcomeres because of the change in ventricular geometry, allowing the LV to maintain a normal chamber performance even though the sarcomeres may have a depressed contractile state. On the other hand, the developed stress index, which indicates the myocardial capacity of force generation normalized by wall surface area, would be preferred (15). However, one would argue that even developed stress has inherent drawbacks. For example, the conversion of pressure-overload data to stress-strain re- quires a definitive assumption about the geometrical shape of the left ventricle, which may greatly change depending on the type of hemodynamic loading. These considerations are keeping this issue as a topic of debate (22-25). In a recent study Esposito et al. (26) analyzed pressure-overloaded mouse hearts with or without hypertrophy and showed that cardiac hypertrophy prevented the increase in wall stress. There was a progressive decrease of PVR and $+\mathrm{dP} / \mathrm{dt}$ indexes, which was not influenced by hypertrophy. In the cited study, the slope of the end-systolic SSR did not reflect myocardial dysfunction.

In the present study, the PVR indicated preserved contractile state in 63-week-old rats, in agreement with Conrad et al. (21). Therefore, we may conclude that PVR is the most useful index for evaluating SHR without signs of heart failure. However, it should be pointed out that the systolic PVR is a questionable index of contractility in isolated rat hearts. Several investigators have shown that PVR is curvilinear rather than linear in rat hearts (27-34). These observations add even more uncertainty to the evaluation of contractility of the isolated heart.

Controversy persists regarding volumeoverload myocardial hypertrophy, even when only the infrarenal ACF model is considered. For example, Liu et al. $(6,7)$ reported preserved ventricular function when analyzing LV systolic and diastolic pressure, $+\mathrm{dP} /$ $\mathrm{dt}$, and aortic pressure. Noma et al. (5) reported improved contractility by analyzing $\mathrm{LV}$ systolic and diastolic pressure, $+\mathrm{dP} / \mathrm{dt}$, and cardiac output. Recently, Brower et al. $(2,3)$ analyzed the LV systolic PVR and concluded that myocardial contractility was impaired in rats with volume-overload hypertrophy and ventricular dilatation. Although the mechanisms underlying these discrepancies remain unclear, it should be pointed out that the studies of Liu et al. $(6,7)$ and Noma et al. (5) were performed using female rats while Brower et al. $(2,3)$ used male rats. This means that the differences in 
the results might be related to gender.

The present results regarding ACF rats showed decreased $+\mathrm{dP} / \mathrm{dt}$, LVP and PVR, suggesting reduced contractility. On the other hand, developed stress and the slope of the SSR were increased, a fact that might indicate increased contractility. Regarding the formula used to calculate stress, it is possible to consider that hearts with large volumes present increased wall stress, even with normal or reduced systolic pressure. Grossman et al. (35) proposed the use of SSR rather than PVR to compare hearts of different sizes. However, in the present study we observed that larger ventricles presented higher values of developed stress, even when de- veloped pressure and $+\mathrm{dP} / \mathrm{dt}$ were lower. Thus, it seems that in the presence of ventricular dilatation the use of stress-derived indexes should be avoided, at least in the isovolumetrically beating heart.

The present results show that the indexes of myocardial contractility most frequently used in experimental studies, such as LVP, developed stress and the slopes of both PVR and SSR may present opposite results in the same heart and may be influenced by ventricular geometry. We concluded that these indexes together with $\mathrm{dP} / \mathrm{dt}$ should be taken into account for proper evaluation of contractile state, in the isovolumetrically beating isolated heart.

\section{References}

1. Spann Jr JF, Buccino RA, Sonnenblick EH \& Braunwald E (1967). Contractile state of cardiac muscle obtained from cats with experimentally produced ventricular hypertrophy and heart failure. Circulation Research, 21: 341-354.

2. Brower GL, Heneger JR \& Janicki JS (1996). Temporal evaluation of left ventricular remodeling and function in volume-overload hypertrophy. American Journal of Physiology, 271: H2071-H2078.

3. Brower GL \& Janicki JS (2001). Contribution of ventricular remodeling to pathogenesis of heart failure in rats. American Journal of Physiology, 280: H674-H683.

4. Fioretto JR, Queiroz SS, Padovani CR, Matsubara LS, Okoshi K \& Matsubara BB (2002). Ventricular remodeling and diastolic myocardial dysfunction in rats submitted to protein-calorie malnutrition. American Journal of Physiology, 282: H1327-H1333.

5. Noma K, Brändle M, Rupp H \& Jacob R (1990). Left ventricular performance in rats with chronic overload due to arterio-venous shunt. Heart Vessels, 5: 65-70.

6. Liu Z, Hilbelink DR, Crockett WB \& Gerdes AM (1991). Regional changes in hemodynamics and cardiac myocyte size in rats with aortocaval fistulas. 1. Developing and stabilised hypertrophy. Circulation Research, 69: 52-58.

7. Liu Z, Hilbelink DR, Crockett WB \& Gerdes AM (1991). Regional changes in hemodynamics and cardiac myocyte size in rats with aortocaval fistulas. 2. Long-term effects. Circulation Research, 69: 59-65.

8. Marino TA, Kent RL, Uboh CE, Fernandez E, Thompson EW \& Iv GC (1985). Structural analysis of pressure versus volume overload hypertrophy of cat right ventricle. American Journal of Physiology, 18: $\mathrm{H} 371-\mathrm{H} 379$.

9. Zile MR, Tomita M, Nakano K, Mirsky Y, Usher B, Lindrth J \& Carabello BA (1991). Effects of left ventricular volume overload produced by mitral regurgitation on diastolic function. American Journal of Physiology, 261: H1471-H1480.

10. Badke FR, White FC, Lewinter M, Covell JW, Andres J \& Bloon CM
(1981). Effects of experimental volume overload hypertrophy on myocardial blood flow and cardiac function. American Journal of Physiology, 241: H564-H570.

11. Lavandero S, Cartagena G, Guarda E, Corbalán R, Godoy I, SapagHagar M \& Jalil J (1993). Changes in cyclic AMP dependent protein kinase and active stiffness in heart volume overload model of heart hypertrophy. Cardiovascular Research, 27: 1634-1638.

12. Pouleur H, Rousseau MF, Petein M, Van Mechelen H \& Charlier AA (1983). Effects of chronic volume overload on left ventricular response to tachycardia. American Journal of Physiology, 245: H218H228.

13. LeWinter MM \& VanBuren $P$ (2002). Myofilament remodeling during the progression of heart failure. Journal of Cardiac Failure, 8: S271-S275.

14. Tombe PP (2003). Cardiac myofilaments: mechanics and regulation. Journal of Biomechanics, 36: 721-730.

15. Murad N \& Tucci PJ (1999). Developed pressure data may provide misinformation when used alone to evaluate systolic function in isovolumetric left ventricle preparations. Brazilian Journal of Medical and Biological Research, 32: 773-776.

16. Braunwald E (1992). Pathophysiology of heart failure. In: Braunwald E (Editor), Heart Disease. A Textbook of Cardiovascular Medicine. 4th edn. WB Saunders, Philadelphia, PA, USA.

17. Deanda AJR, Komeda M, Moon MR, Green GR, Bolger AF, Nikolic SD, Daughters 2nd GT \& Miller DC (1998). Estimation of regional left ventricular wall stresses in intact canine hearts. American Journal of Physiology, 275 (Part 2): H1879-H1885.

18. Garcia R \& Diebold S (1990). Simple, rapid and effective method of producing aortocaval shunts in the rat. Cardiovascular Research, 24: 430-432.

19. Weber KT, Janicki JS \& Reeves RC (1976). Factors influencing left ventricular shortening in isolated canine heart. American Journal of Physiology, 230: 419-426.

20. Suga H \& Sagawa K (1974). Instantaneous pressure-volume rela- 
tionships and their ratio in excised, supported canine left ventricle. Circulation Research, 35: 117-126.

21. Conrad $\mathrm{CH}$, Brooks WW, Hayes JA, Sen S, Robinson KG \& Bing $\mathrm{OHL}$ (1995). Myocardial fibrosis and stiffness with hypertrophy and heart failure in the spontaneously hypertensive rat. Circulation, 91: 161-170.

22. Belcher D, Boerboom LE \& Olinger G (1985). Standardization of endsystolic pressure-volume relation in dog. American Journal of Physiology, 249: H547-H553.

23. Bogen DK, Ariel Y, McMahon TA \& Gaasch WH (1985). Measurement of peak systolic elastance in intact canine circulation with servo pump. American Journal of Physiology, 249: H585-H593.

24. Mirsky I, Tajimi T \& Peterson KL (1987). The development of the entire end-systolic pressure-volume and ejection fraction afterload relations: a new concept of systolic myocardial stiffness. Circulation, 76: 343-356.

25. Nakano KM, Swindle M, Spinale F et al. (1991). Depressed contractile function due to canine mitral regurgitation improves after correction of the volume overload. Journal of Clinical Investigation, 87: 2153-2161.

26. Esposito G, Rapaccioulo A, Sathyamangla V, Prasad N, Takaoka H, Thomas SA, Koch WJ \& Rockman HA (2002). Genetic alterations that inhibit in vivo pressure-overload hypertrophy prevent cardiac dysfunction despite increased wall stress. Circulation, 105: 82-92.

27. Tachibama H, Takaki M, Lee S, Ito H, Yamaguchi H \& Suga H (1997). New mechanoenergetic evaluation of left ventricular contractility of in situ rat hearts. American Journal of Physiology, 272: H2671$\mathrm{H} 2678$.

28. Lee S, Ohga $Y$, Tachibana $H$, Syuu $Y$, Ito $H$, Harada $M$, Suga $H$ \& Takaki M (1998). Effects of myosin isozyme shift on curvilinearity of the left ventricular end-systolic pressure-volume relation of in situ rat hearts. Japanese Journal of Physiology, 48: 445-455.

29. Kishi T, Nakahashi K, Ito H, Taniguchi S \& Takaki M (2001). Effects of milrinone on left ventricular end-systolic pressure-volume relation of in situ rat hearts. Clinical and Experimental Pharmacology and Physiology, 28: 737-742.

30. Hata Y, Sakamoto T, Hosogi S, Ohe T, Suga H \& Takaki M (1998). Linear $\mathrm{O}_{2}$ use-pressure-volume area relation from curved end-systolic pressure-volume relation of the blood-perfused rat ventricle. Japanese Journal of Physiology, 48: 197-204

31. Tsuji T, Ohga Y, Yoshikawa Y et al. (1999). New index for oxygen cost of contractility from curved end-systolic pressure-volume relations in cross-circulated rat hearts. Japanese Journal of Physiology, 49: 513-520.

32. Misawa H, Kohzuki H, Sakata S, Ohga Y \& Takaki M (2001). Oxygen wasting for $\mathrm{Ca}^{2+}$ extrusion activated by partial inhibition of sarcoplasmic reticulum $\mathrm{Ca}^{2+}$-ATPase by cyclospiazonic acid in rat left ventricles. Japanese Journal of Physiology, 51: 99-108.

33. Sakata S, Ohga Y, Abe T, Tabayashi N, Kobayashi S, Tsuji T, Kohzuki H, Misawa H, Taniguchi S \& Takaki M (2001). No dependency of new index for oxygen cost of left ventricular contractility on heart rates in the blood-perfused excised rat heart. Japanese Journal of Physiology, 51: 177-185.

34. Tsuji T, Ohga Y, Yoshikawa Y et al. (2001). Rat cardiac contractile dysfunction induced by $\mathrm{Ca}^{2+}$ overload: Possible link to the proteolysis of fodrin. American Journal of Physiology, 281: 1286-1294.

35. Grossman W, Jones D \& McLaurin LP (1975). Wall stress and patterns of hypertrophy in the human left ventricle. Journal of Clinical Investigation, 56: 56-64. 